\title{
Central Nervous System Monoamine Correlates of Social Dominance in Cynomolgus Monkeys (Macaca fascicularis)
}

Jay R. Kaplan, Ph.D., Stephen B. Manuck, Ph.D., M. Babette Fontenot, D.V.M., Ph.D., and J. John Mann, M.D.

Social dominance is a fundamental component of both human and nonhuman primate sociality. However, its neurobiological correlates remain incompletely understood. We evaluated the association between dominance status and monoamine metabolite concentrations in cisternal cerebrospinal fluid (CSF) in adult male $(n=25)$ and female $(n=21)$ cynomolgus macaques (Macaca fascicularis) housed in unisexual social groups. Concentrations of the metabolites of dopamine (homovanillic acid [HVA]), norepinephrine (3-methoxy-4-hydroxyphenylglycol [MHPG]) and serotonin (5-hydroxyindoleacetic acid [5HIAA]) were assayed. Dominant monkeys, both males and females, had significantly higher CSF HVA concentrations than did subordinates ( $\mathrm{p}$ values $<.05$ ). Among males, but not females, dominants also had lower CSF 5-HIAA than subordinates ( $\mathrm{p}<.05)$. The Dominance-HVA association observed here is consistent with recent speculation that social extraversion, a dominance-related personality trait in humans, may also reflect heightened central nervous system dopaminergic activity.

[Neuropsychopharmacology 26:431-443, 2002]

(c) 2002 American College of Neuropsychopharmacology.

Published by Elsevier Science Inc.
KEY WORDS: Serotonin; Dopamine; Behavior; Personality; Macaque; Aggression

Social dominance reflects an asymmetry of relationship among individuals, as defined by the outcomes of dyadic encounters of a competitive or agonistic nature,

From the Wake Forest University School of Medicine, WinstonSalem, North Carolina (JRK), Department of Psychology, Clinical Psychology Center, University of Pittsburgh, Pittsburgh, Pennsylvania (SBM), Division of Behavioral Sciences, New Iberia Research Center, New Iberia, LA (MBF), Columbia University, New York, New York (JJM), and Department of Neuroscience, New York State Psychiatric Institute, New York, New York (JJM).

Corresponding Author: Jay R. Kaplan, Ph.D., Professor of Pathology (Comparative Medicine), Wake Forest University School of Medicine, Medical Center Blvd., Winston-Salem, NC 27157-1040, Tel.: (336) 716-1522, Fax: (336) 716-1515, E-mail: jkaplan@ wfubmc.edu

Received February 12, 2000; revised July 5, 2001; accepted July 25, 2001.

Online publication: 7/27/01 at www.acnp.org/citations/Npp 072701155. and has long been thought to represent a fundamental component of sociality in nonhuman primates (Bernstein 1981; Silk 1987; Walters and Seyfarth 1987). Dominance-related behaviors may also comprise a primary axis of interpersonal behavior in the structure of human social relationships (Wiggins and Trapnell 1996). Additionally, this concept is often extended, in people, to include dimensional variation in personality traits such as extraversion or social potency (Wiggins and Pincus 1992; Wiggins and Trapnell 1996). Recent studies also suggest that differences in dominance status in monkeys and dominance-related personality traits in humans partially reflect variation in aspects of central nervous system monoaminergic activity (Raleigh et al. 1983, 1991; Depue et al. 1994; Higley et al. 1996a, 1996b; Shively 1998).

In monkeys, serotonin has figured prominently in behavioral research relating to social dominance. For example, male vervet monkeys (Cercopithecus aethiops) become dominant in their social groups following treat- 
ment with either the serotonin precursor tryptophan or the serotonin reuptake inhibitor fluoxetine, and take a subordinate position when treated chronically with the serotonin releasing/depleting agent fenfluramine (chronic administration depletes serotonin) (Raleigh et al. 1991). Naturally-occurring differences in cerebrospinal fluid (CSF) concentrations of the serotonin metabolite 5-hydroxyindoleacetic acid (5-HIAA) also covary positively with dominance rank in female rhesus monkeys (Macaca mulatta), although a similar relationship has not been clearly described for adult male rhesus monkeys (Higley et al. 1996a). In contrast, dominant female cynomolgus monkeys (M. fascicularis) exhibit lower central serotonergic activity (as indexed by a low prolactin response to the serotonin agonist fenfluramine) than subordinates (Shively et al. 1995). Likewise, it is reported that dominant male and female talapoin monkeys (Miopithecus talapoin) have lower CSF 5-HIAA concentrations than do either middle or low ranking animals (Yodyingyuad et al. 1985). Finally, serotonin may not be the only monoamine associated with social status in nonhuman primates, as results of other studies suggest that dominant and subordinate cynomolgus monkeys differ in indices of central dopaminergic activity. For example, dominant female monkeys exhibit higher binding potential to a selective dopamine D2 receptor antagonist ligand than subordinates (Grant et al. 1998), and exhibit a greater prolactin response to the dopamine antagonist haloperidol (Shively 1998).

This apparent inconsistency of association across studies and species is not readily explained. Nor do studies of human subjects provide much additional insight, as relevant investigations are few. Also, what data do exist focus primarily on monoamine correlates of personality traits, such as extraversion, that probably contribute to, rather than define, the outcome of dominance interactions (Zuckerman 1995). Nonetheless, the results of these few studies also emphasize the potential importance of dopaminergic activity in the expression of dominance-related components of personality (e.g., ambition, mastery, and achievement motivation) (Netter and Rammsayer 1991; Depue et al. 1994).

To further examine the relationships between the biogenic amines and social dominance, we measured the CSF metabolites of serotonin (5-HIAA), dopamine (homovanillic acid, (HVA)), and norepinephrine (3methoxy-4-hydroxyphenylglycol (MHPG)) in two samples of cynomolgus monkeys, one comprised of 25 males, and the other of 21 females. Work by numerous investigators suggests that, in monkeys, monoamine metabolite concentrations in CSF are stable over time and across environments; furthermore, CSF concentrations observed in young animals are often predictive of those observed in the same individuals later in life. (Lewis et al. 1990; Higley et al. 1991, 1996b; Raleigh et al. 1992). In the current study, animals were housed in unisexual groups of five or six animals (five groups of males, four groups of females) that were initially composed of social strangers, but which had been allowed to stabilize for at least one year prior to CSF collection. Dominance relationships were monitored routinely in all groups by noting the outcome of agonistic encounters (Sade 1967, 1973). The use of numerous small groups - rather than one or two larger ones - meant that there were several animals at each categorical rank. The data from these animals were aggregated across groups by rank to address three objectives: (1) identify associations between CSF monoamine metabolite concentrations and social dominance in unisexual groups of unrelated monkeys; (2) determine whether any such associations characterize both males and females; and (3) in females, evaluate the relationships among ovarian cyclicity, monoaminergic activity, and dominance. For clarity, the methods and results of the male and female studies are presented separately.

\section{MALE STUDY METHODS}

\section{Subjects and Study Design}

Animals were 25 male cynomolgus macaques imported as adults (as determined by the presence of fullyerupted canines) from Indonesia and housed in groups of five monkeys each. Body weight and age did not vary significantly across groups. Genetic relationships among the animals were unknown. All animals were trained to enter a squeeze cage from their home pen to facilitate anesthesia and sampling. The study monkeys comprised one-third of the animals in a 28-month experiment evaluating the effects of diet and social stress on the progression of coronary artery atherosclerosis. The remaining two-thirds of the animals were treated identically except that group memberships were reorganized monthly during either the first or second halves of the experiment (e.g., Kaplan and Manuck 1989). All animals consumed an atherogenic diet deriving approximately $45 \%$ of calories from fat, $17 \%$ from protein, and $38 \%$ from carbohydrates, and containing $0.25 \mathrm{mg} / \mathrm{Cal}$ cholesterol. Due to the potential confound associated with the social perturbation, animals in reorganized groups were not included in the current study. All animal procedures were conducted in accordance with federal and state regulations and with the approval of our institution's Animal Care and Use Committee. Wake Forest University is fully accredited by AAALAC.

\section{Behavioral Observations}

The behavioral repertoire of macaques living in small groups has been described previously by others and us (Welker et al. 1979; Kaplan and Manuck 1989; Bu- 
tovskaya et al. 1995; Kaplan et al. 1996). This repertoire consists of a relatively limited number of stereotyped motor patterns that may be characterized as aggressive, submissive, affiliative, or indeterminate (events that may occur in a number of different contexts) (Kaplan et al. 1996). In this study, motor patterns were combined into specific, mutually exclusive behavioral episodes (e.g., fight wins, losses, grooming, passive body contact) and recorded from each social group using a combination of all-occurrence and scan sampling (Kaplan et al. 1996). Each group was observed twice per week at 30 min per sample and balanced for time of day. A total of 224 such samples were obtained from every social group. For purposes of analysis, the average rates (per hour) of fight wins and losses and the percentage of time spent grooming, being groomed, alone (not within touching distance of another animal), close (within touching distance), or in passive contact were calculated for each animal for the entire 28-month experiment (Kaplan et al. 1996). All behavioral data were recorded with the aid of an electronic data collection device (Tandy TRS Model 100). After collection, these data were transmitted to a mainframe computer for management and analysis.

\section{Determination of Dominance}

As in previous studies, social status was determined on the basis of fight outcomes in dyadic encounters (Kaplan et al. 1982, 1990, 1996). A fight was defined as an attack of any intensity followed by flight of any intensity (Sade 1967). Winners of fights were those animals that elicited unambiguous flight gestures (cowers or grimaces) from their targets (Sade 1967, 1973). In a given social group, the animal that was able to defeat all others (as evidenced by the elicitation of submissive gestures) was designated first in rank for that period of observations. The animal that defeated all but the firstranking monkey was designated second in rank, and so forth. (Kaplan et al. 1982; Kaplan and Manuck 1989). In instances of uncertainty, tied ranks were assigned; such ties were infrequent, occurring in less than $1 \%$ of dyads in the current study ( $\mathrm{n}=7$ ties in 1400 possible dyads). Interobserver reliability for the assignment of dominance ranks was high, with Cohen's Kappa $=0.93$ (unweighted) across observers.

Fight outcomes were summarized at 2-week intervals for each animal. All animals therefore had two equivalently spaced rank determinations for each experimental month. For purposes of analysis with respect to both CSF monoamine metabolites (which were sampled on a single occasion at the end of the experiment, described below) and rates of behavioral performance, ranks were averaged over the entire 28 months of the experiment. Animals that on average occupied a rank of one or two in their social groups were catego- rized as dominant, with the rest designated subordinate for the experiment. This method of categorizing animals helps correct for idiosyncratic associations among variables that may obtain in any one social group by aggregating among animals of similar rank across all groups. The same approach has been used previously in similarly designed studies with respect to the prediction of coronary artery atherosclerosis, heart rate, adrenocortical response to challenge, and resistance to infection. (Kaplan et al. 1982, 1986, 1990; Cohen et al. 1997). Nonetheless, because average rank for the experiment is based largely on data separated in time from the collection of CSF, additional analyses were conducted based on ranks determined at the time of CSF collection.

\section{Cerebrospinal Fluid Sampling and Analysis}

An escape door was built into each pen. Animals were trained to move through this door into a squeeze cage, where they were subsequently anesthetized for sampling. This procedure was generally completed within $30 \mathrm{~s}$ for each social group, with animals entering the capture box virtually simultaneously. On CSF sample days, the animals were moved into squeeze cages between 8:00 and 10:30 A.M. After entering the squeeze cage, the animals were anesthetized with an intramuscular injection of ketamine $(15 \mathrm{mg} / \mathrm{kg})$. Within $15-20$ min after receiving the injection, a 1.0-1.5 cc cerebrospinal fluid sample was obtained from the cisterna magna with a 25 gauge $\times 2$-inch needle fitted to a sterile 3 -cc syringe (Kaplan et al. 1999). Usable samples were obtained from all monkeys, with no more than three attempts made for any animal. Following collection, samples were centrifuged to remove debris and immediately stored at $-70^{\circ} \mathrm{C}$ until analyzed. The CSF monoamine metabolites of serotonin (5-HIAA), dopamine (HVA), and norepinephrine (MHPG) were assayed by high performance liquid chromatography with an electrochemical detector using the method described by Scheinin et al. (1983). The coefficient of variation for all metabolites was less than $10 \%$ and the sensitivity was $0.5 \mathrm{pmol} / \mathrm{in}-$ jection. Due to experimental constraints, all animals were sampled on a single occasion. However, data from our own and other laboratories indicate relative stability of monoamine metabolite concentrations. (Kaplan et al. 1994; Higley et al. 1996a; Shively 1998; see study 2, below).

\section{Body Weight}

Body weights of all animals were assessed monthly for evaluation in relation to rank and CSF monoamine metabolites. Body weight averaged over the entire experiment as well as body weight at the time of CSF sampling were used in these analyses. 


\section{Statistical Analyses}

To confirm the presence of behavioral differences between animals categorized as dominant and subordinate, the rates of fight wins, the rate of fight losses, and the percentage of time spent grooming, being groomed, alone, or in physical contact with other monkeys were compared nonparametrically by Mann-Whitney U tests. Parametric comparisons (by $t$-test) were conducted to determine whether animals categorized as dominant and subordinate differed in monoamine metabolite concentrations. Also, correlations were calculated among the monoamine metabolites and between the monoamine metabolites and average dominance rank (Pearson's $r$ ). Where necessary, the meaning of bivariate correlations was clarified by use of partial correlations. Correlations between CSF monoamine values and rank assessed at the time of CSF sampling were done nonparametrically (Spearman's rho). By convention, the highest dominance rank in a social group is one; hence, the sign of all correlations involving rank was reversed. Where necessary, monoamine data were subjected to standard linear transformations to meet assumptions of parametric analysis. Figures and tables, however, contain untransformed values. All tests of significance were 2 -tailed.

The above data analysis is predicated on the presence of relatively stable dominance ranks. The stability of dominance was evaluated in two ways. Spearman's rank order correlation was used to compare dominance status across all 56 ranking periods. The median correlation (rho) between any two rank determinations in this 1540 cell matrix was $>0.90$. Furthermore, across the entire experiment, we identified the number of animals that changed categorical ranks from "dominant" (i.e., 1 or 2) to "subordinate" (i.e., 3, 4, or 5). A total of 1400 categorical changes were possible $(25$ monkeys $\times 56$ rank determinations). Such changes occurred only three times, two of which were in the first ranking period (just after the monkeys were placed together in social groups). We conclude from these data that the rankings were stable across the study. Nonetheless, we removed these three animals from the analysis and recalculated the $t$ scores comparing CSF monoamine metabolites in dominants and subordinates; the statistical results were virtually identical.

\section{MALE RESULTS}

\section{Behavioral Differences between Dominant and Subordinate Monkeys}

Table 1 summarizes rates of fight wins and losses, as well as the percentage of time animals categorized as dominant or subordinate (based on the entire experiment) spent grooming, being groomed, in contact, close, or alone. Naturally, dominant animals exhibited high rates of fight wins while subordinates exhibited similarly high rates of fight losses $(p$ values $<.001)$. Dominant monkeys were also groomed more than subordinates $(p<.01)$ and tended to spend less time alone $(p=.07)$. The same associations were observed in correlational analyses. Hence, dominance rank was positively associated with fight wins ( $r h o=0.78, p<.001$ ), negatively associated with losses ( rho $=0.90, p<.001)$, positively with percent of time being groomed (rho $=$ $0.63, p<.001$ ), and marginally (negatively) with time spent alone ( $r h o=-0.35, p=.08)$.

\section{Monoamine Metabolites and Dominance Status}

The 11 animals characterized as dominant and 14 judged subordinate over the entire experiment were compared with respect to the three monoamine metabolites by means of $t$-tests. A logarithmic transformation was applied to metabolite data prior to analysis to normalize distributions and achieve homogeneity of group variances. The results of these analyses are depicted in Figure 1. Animals categorized as dominant had higher HVA concentrations $\left(t_{23}=2.16, p=.04\right)$ and tended to have higher MHPG concentrations $\left(t_{23}=2.04, p=.052\right)$ than did subordinates. Dominant and subordinate animals did not differ by CSF concentrations of 5-HIAA. When data from animals ranking one or two at the time of CSF collection (i.e., dominant, $\mathrm{n}=10$ ) were compared with values from those ranking three, four, or five (i.e., subordinate, $\mathrm{n}=15$ ), only the HVA difference remained significant $\left(t_{23}=2.61, p<.02\right)$. The same analysis applied to the entire population of males (i.e., including those that were in repeatedly reorganized groups) revealed similar results with respect to both HVA $\left(t_{65}=2.52, p=.01\right)$ and MHPG $\left(t_{65}=2.37, p=\right.$ $.02)$. These analyses were also significant when limited to animals living in groups not being reorganized at the time of sampling (HVA: $t_{45}=2.91, p<.01$; MHPG: $t_{45}=$ $2.37, p=.02)$. However, these analyses were not significant when applied just to those animals that were in groups being reorganized at the time of sampling, suggesting that this social manipulation may obscure the dominance-monoamine associations.

Correlations among the primary variables are shown in Table 2. MHPG covaried significantly with average rank $(r=0.41, p<.05)$, but only marginally with rank at the time CSF was collected ( $r h o=0.34, p=.10$ ). There was also a marginally significant correlation between MHPG and HVA ( $r=0.39, p=.05)$. As might be expected from the categorical comparisons, average dominance rank correlated significantly with HVA concentration $(r=0.52, p<.01)$. Rank at the time of CSF sampling also correlated significantly with HVA ( $r h o=$ $0.42, p<.05)$, though not with MHPG. Finally, there was a high correlation between CSF concentrations of 
Table 1. Median (range) Behavioral Performance of Male Cynomologus Monkeys Characterized as Dominant $(\mathrm{n}=11)$ or Subordinate $(\mathrm{n}=14)^{\mathrm{a}}$

\begin{tabular}{lccc}
\hline Category & Dominant $^{\mathbf{b}}$ & Subordinate $^{\mathbf{c}}$ & $p^{\mathbf{d}}$ \\
\hline Rate of Fight Wins/Hr & $4.3(1.8-9.9)$ & $1.4(0.0-4.3)$ & .001 \\
Rate of Fight Losses/Hr & $0.5(0.0-4.0)$ & $4.8(2.01-8.00)$ & .001 \\
\% Time Grooming & $10.2(2.6-16.8)$ & $7.4(2.5-20.3)$ & NS \\
\% Time Being Groomed & $12.5(4.8-18.9)$ & $6.0(0.7-10.5)$ & .005 \\
\% Time in Contact & $34.9(21.9-55.4)$ & $32.6(11.3-61.2)$ & NS \\
\% Time Close & $9.3(5.0-15.1)$ & $9.2(5.9-16.6)$ & NS \\
\% Time Alone & $33.9(19.9-41.0)$ & $38.1(20.6-66.5)$ & .07 \\
\hline
\end{tabular}

\footnotetext{
${ }^{a}$ Based on 240 30-min observations per social group.

${ }^{b}$ Dominant animal had an average rank of one or two.

c Subordinate animals had an average rank of three or lower.

${ }^{\mathrm{d}}$ Comparisons by Mann-Whitney U.
}

HVA and 5-HIAA ( $r=0.66, p<01)$, which is consistent with previous observations in monkeys and people (Kaplan et al. 1999).

The above pattern of correlations suggested that the MHPG-HVA-Rank associations might not be independent. Partial correlations showed the HVA association with Rank to remain significant when controlling for MHPG (partial $r_{\text {HVA,RANK.MHPG }}=0.42, p<.05$ ), whereas MHPG no longer covaried with rank after partialling out the HVA concentration (partial $r_{\mathrm{MHPG}, \mathrm{RANK} . \mathrm{HVA}}=$ 0.22 , NS). Additionally, the high correlation between HVA and 5-HIAA implied the presence of shared variance between these two metabolites. Accordingly, these two variables also were examined with respect to rank via partial correlation. HVA still correlated significantly with Rank, after partialling 5-HIAA (partial $r_{\text {HVA,RANK.HIAA }}=$ $0.64, p<.0010$ ); interestingly, 5-HIAA now also correlated significantly with Rank, after adjustment for HVA

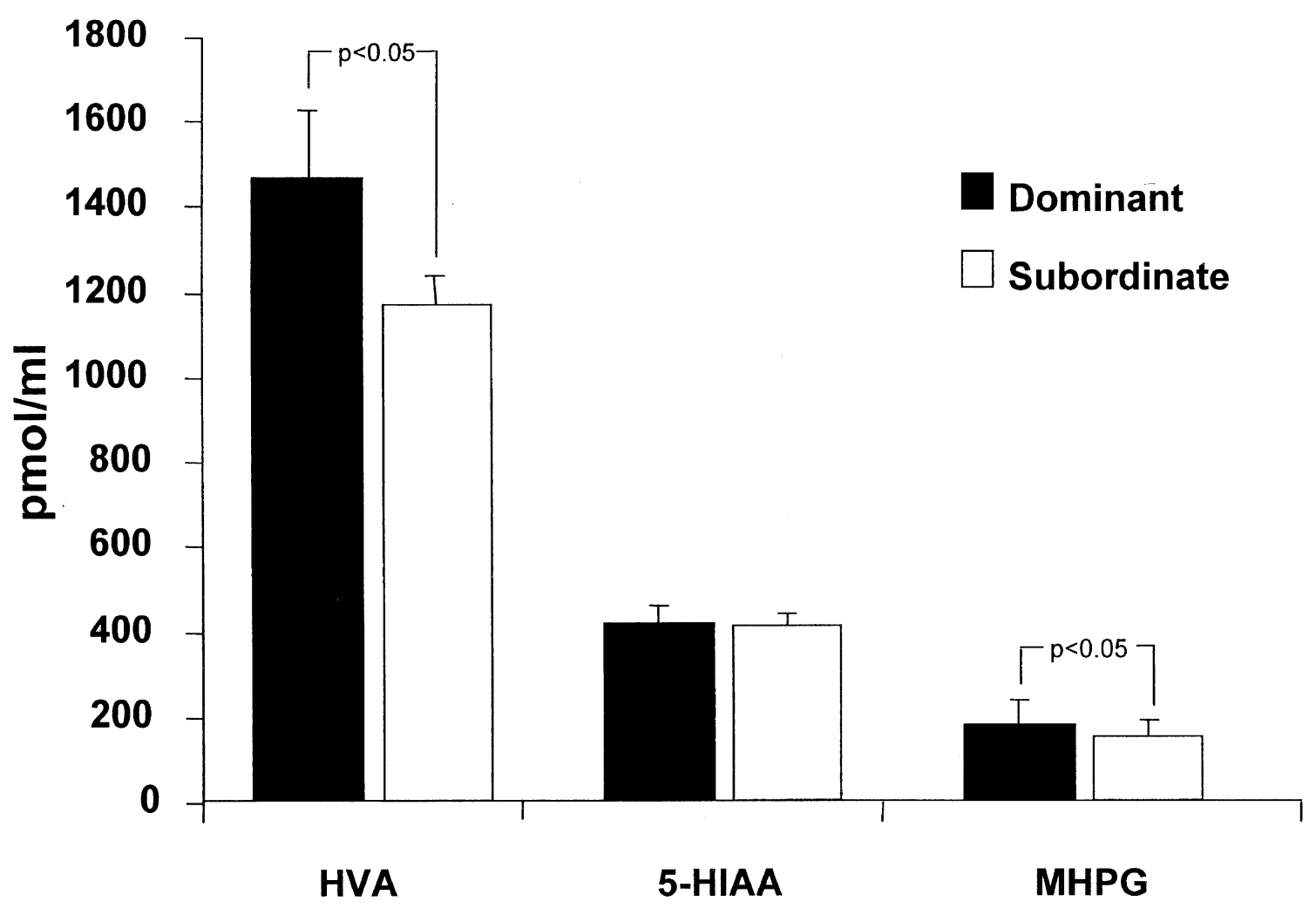

Figure 1. CSF HVA, 5-HIAA, and MHPG concentrations (mean + standard error) of dominant $(\mathrm{n}=11)$ and subordinate $(\mathrm{n}=$ 14) males. Statistical significance determined by $t$-test. The significant difference associated with MHPG is eliminated by partial correlation analysis; the same analysis unmasks a significant inverse association between dominance and 5-HIAA (see text for details). 
Table 2. Correlations for Male Cynomolgus Monkeys in Study $1, n=25^{\mathrm{a}, \mathrm{b}}$

\begin{tabular}{lccccccc}
\hline & MHPG & 5-HIAA & HVA & $\begin{array}{c}\text { Average }^{\mathrm{b}} \\
\text { Weight }\end{array}$ & $\begin{array}{c}\text { Final }^{\mathbf{b}} \\
\text { Weight }\end{array}$ & $\begin{array}{c}\text { Average }^{\mathbf{b}} \\
\text { Rank }\end{array}$ & $\begin{array}{c}\text { Final }^{\mathbf{b}} \\
\text { Rank }\end{array}$ \\
\hline MHPG & --- & 0.21 & 0.39 & -0.38 & -0.36 & $0.41^{*}$ & 0.34 \\
5-HIAA & & --- & $0.64^{* *}$ & 0.14 & 0.06 & 0.05 & 0.02 \\
HVA & & & --- & 0.22 & 0.16 & $0.52^{* *}$ & $0.42^{*}$ \\
Average Weight & & & & --- & $0.91^{* *}$ & 0.06 & 0.00 \\
Final Weight & & & & & ---- & 0.08 & 0.04 \\
Average Rank & & & & & & --- & $0.88^{* *}$ \\
\hline
\end{tabular}

a Values are Pearson's $r$ except the last column (Final Rank), which is Spearman's rho.

$\mathrm{b}$ "Average Weight" and "Average Rank" refer to values averaged over the entire experiment; "Final Weight" and "Final Rank" refer to those values obtained at the time of CSF sampling. Weight of males was $6.15 \pm 1.12 \mathrm{~kg}($ mean $\pm \mathrm{SD})$

${ }^{*} p<.05$

${ }^{* *} p<.01$

(partial $r_{\text {HIAA,RANK.HVA }}=-0.44, p<.05$ ). It appears therefore that the simple bivariate analysis obscured an inverse correlation between 5-HIAA and Rank, owing perhaps to the high covariation of the 5-HIAA and HVA metabolites in CSF.

\section{FEMALE STUDY METHODS}

\section{Subjects and Study Design}

This study was comprised of female monkeys imported from Indonesia as adults (based on dentition), and housed in one group of five animals and three groups containing six monkeys $(n=23)$. Illness prevented two monkeys from being sampled, leaving the 21 animals whose data are reported here. These animals were in the control (non-drug) condition of a study examining the effects of oral contraceptives on the progression of atherosclerosis (Kaplan et al. 1995). Like the animals in Study 1 , these monkeys also consumed a diet relatively high in fat and cholesterol ( $45 \%$ of calories from fat, $38 \%$ from carbohydrates, and $17 \%$ from protein, with $0.28 \mathrm{mg} /$ Cal cholesterol), and were trained to enter a squeeze cage from their home cage to facilitate anesthesia and sampling. Animals in this study were sampled for plasma concentrations of progesterone (to evaluate menstrual cycle phase and quality) and for CSF. As in study 1 , all animal procedures were conducted in accordance with federal and state regulations and with the approval of our institution's Animal Care and Use Committee.

\section{Behavioral Observations}

Only dominance rank was evaluated in this study. Ad libitum samples (Altmann 1974) were recorded from each group for 30 min per week or until all dyads within the group had been observed to interact agonistically.

\section{Determination of Dominance Status}

As in Study 1, the rank of each animal was determined on the basis of fight outcomes. For purposes of analysis, ranks were averaged from the beginning of the experiment through the collection of CSF samples (approximately 10 months). Animals that ranked three or higher in groups of six, or one or two in groups of five were categorized as dominant; the rest were designated subordinate. By these criteria, there were 9 dominant and 12 subordinate monkeys.

\section{Cerebrospinal Fluid Sampling and Analysis}

The techniques used for the collection and analysis of CSF monoamine metabolites were the same as employed in Study 1. However, unlike the males, where only one CSF sample was taken, four separate samples were collected from each female. Starting in week 35 of the study, cisternal CSF samples were collected from each study animal on four sequential Wednesdays, thus providing an opportunity to obtain representative material from the luteal and follicular phases of the menstrual cycle.

\section{Steroid Hormone Collection and Analysis}

On Mondays, Wednesdays (except as noted below) and Fridays, during study weeks 30 to 40 and beginning at 0800, each animal was placed in a single cage and a 5.0 cc blood sample was obtained by femoral sample without anesthesia for progesterone assay. During weeks 35 to 38 , the Wednesday samples for progesterone were taken coincident with the CSF sampling, which involved ketamine restraint. Following blood collection, samples were centrifuged and the resulting serum was removed and stored at $-20^{\circ} \mathrm{C}$ until assayed for progesterone concentration. Progesterone concentrations were determined by radioimmunoassay using a commercially available kit (Diagnostic Products Corp, Los Angeles, CA). 


\section{Determination of Menstrual Cyclicity}

Menstrual cycle stage was based on progesterone concentration at the time of CSF sampling. The follicular phase was defined by progesterone concentrations less than 2.0 $\mathrm{ng} / \mathrm{ml}$, whereas the luteal phase was defined by progesterone concentrations greater than or equal to $2.0 \mathrm{ng} / \mathrm{ml}$ (Adams et al. 1985). Monoamine metabolite concentrations were averaged separately for luteal and follicular phases. Four animals had progesterone concentrations that did not exceed $2.0 \mathrm{ng} / \mathrm{ml}$ at any time during the 4-week CSF sampling period and were thus judged anovulatory for this time period. These animals were excluded from the analyses assessing the effects of menstrual cycle phase on CSF monoamine metabolite concentrations. Finally, a "peak" luteal progesterone concentration was calculated for each animal. This value was determined by averaging the highest progesterone concentration observed during the luteal phase of each menstrual cycle throughout the 10-week blood sampling period (which included the 4-week CSF sampling period).

\section{Statistical Analyses}

All animals lived in unreorganized groups and preliminary analysis revealed that no animals changed ranks spontaneously over the 10-month experimental period that preceded and encompassed the CSF or steroid hormone collections. Rank stability was thus not evaluated statistically in this study. To determine whether dominance or menstrual cycle phase predicted levels of any monoamine metabolite, a series of Status dominant, subordinate $X$ Phase $_{\text {luteal, follicular }}$ ANOVAs were conducted on the 17 cycling animals. All 21 animals were included in a second analysis, which compared dominant and subordinate monkeys with respect to the metabolite concentrations averaged across all four CSF samples (irrespective of cycle phase). Correlations among the monoamine metabolites and peak progesterone were calculated with Pearson's coefficient while correlations involving dominance rank used Spearman's rho. Note that there were uneven numbers of animals in the social groups (three groups of six, one group of five). Regarding the ANOVAs, it should be recalled that animals ranking 1-3 in groups of six $(50 \%)$ were considered dominant while only those ranking 1 or 2 in groups of five (40\%) were similarly considered dominant. For the correlation analyses, animals ranking 5 or 6 were all considered to be ranked 5 .

\section{FEMALE RESULTS}

The Status X Phase ANOVA conducted on data of cycling animals revealed that dominants had significantly higher CSF HVA than did subordinates $\left(\mathrm{F}_{1,15}=7.20\right.$, $p<.02)$, with no significant effects related to Phase or the interaction of these two factors. The dominance effect remained significant in a subsequent analysis applied to the average HVA (across all four samples) for all 21 animals $\left(t_{19}=2.29, p=.03\right)$. Neither Status nor Phase was significant on analysis of MHPG concentrations $\left(\mathrm{F}_{1,15}<1.5, p\right.$ values $\left.=\mathrm{NS}\right)$, nor did Status yield a significant main effect for MHPG on analysis of all 21 animals $\left(t_{19}=-0.10, p=\mathrm{NS}\right)$. Similarly, Status did not significantly differentiate animals with respect to 5HIAA concentrations, either when evaluated only in cycling individuals $\left(\mathrm{F}_{1,15}=1.60, p=\mathrm{NS}\right)$ or across all monkeys $\left(t_{19}=1.11, p=\mathrm{NS}\right)$. However, there was a tendency for 5-HIAA to be higher in the luteal relative to the follicular phase of the menstrual cycle $\left(\mathrm{F}_{1,15}=3.53\right.$, $p=.08)$. Mean values for the three metabolites, by dominance status only, are depicted for all animals in Figure 2. Values of CSF 5-HIAA for dominant and subordinate animals in both phases of the menstrual cycle are shown in Figure 3.

As in Study 1, the correlations between 5-HIAA and HVA and between HVA and dominance were significant, as shown in Table 3. Partial correlations among dominance status and monoamine metabolites revealed no significant associations other than that between dominance and HVA.

Peak luteal phase plasma progesterone concentrations (the average of the highest value in each luteal phase) and dominance rank were correlated significantly. The average plasma progesterone concentration was $10.8 \mathrm{ng} / \mathrm{ml}( \pm 1.5$, standard error) in dominant animals and $6.8 \mathrm{ng} / \mathrm{ml}( \pm 1.0)$ in subordinates $\left(t_{19}=2.28\right.$, $p=.03$ ). Progesterone did not correlate significantly with any of the CSF metabolites. Intercorrelations among the repeated CSF samples taken one week apart yielded average " $r$ " values of 0.61 (5-HIAA), 0.57 (HVA) and 0.76 (MHPG).

\section{DISCUSSION}

We report here associations between CSF monoamine metabolite concentrations and dominance status in small, unisexual groups of unrelated adult macaques originally placed together as social strangers. Among both males and females, dominant monkeys had significantly higher CSF HVA concentrations than did subordinates. On initial analysis, cisternal concentrations of 5-HIAA were not associated with dominance in either sex, and among males, but not females, CSF MHPG was lower in subordinates. However, the MHPG/dominance relationship in males was not significant after correction for the covariation among rank, HVA and MHPG, whereas CSF 5-HIAA covaried inversely with dominance when adjusted for HVA by partial correlation. Dominant females had higher luteal phase, plasma progesterone concentrations than subordinates, an out- 


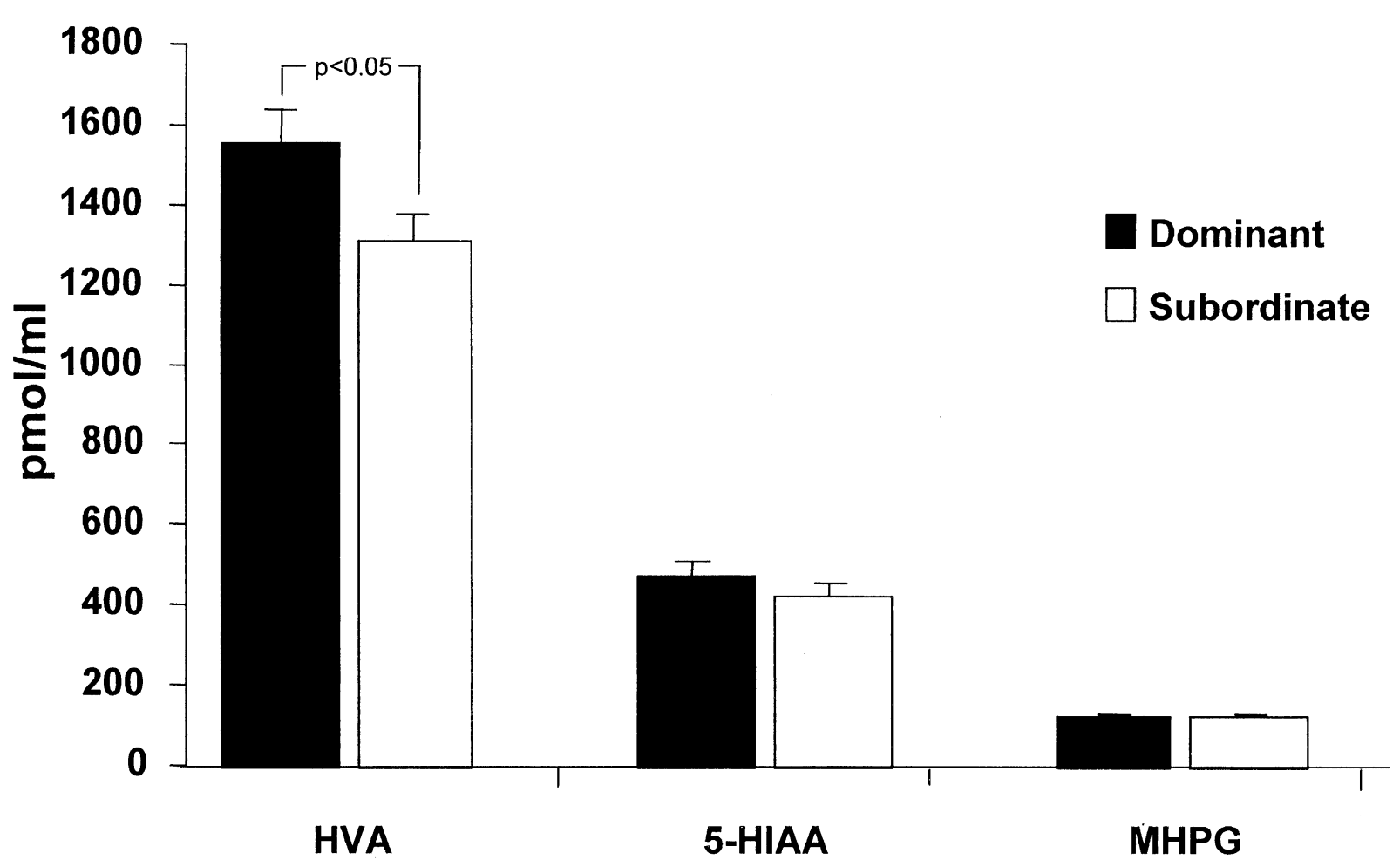

Figure 2. CSF HVA, 5-HIAA, and MHPG concentrations (mean + standard error) in dominant $(\mathrm{n}=9)$ and subordinate $(\mathrm{n}$ $=12$ ) females; values represent the average of four samples per animal, irrespective of cycle phase (luteal, follicular). Statistical significance determined by $t$-test.

come consistent with the lower incidence of ovarian dysfunction previously reported for dominant animals of this species (Adams et al. 1985). There also was a tendency for CSF concentrations of 5-HIAA to be higher in the luteal, as compared with follicular, phase of the menstrual cycle (cf. Eriksson et al. 1994). This finding may merit further investigation in view of the suggested association between premenstrual dysphoric

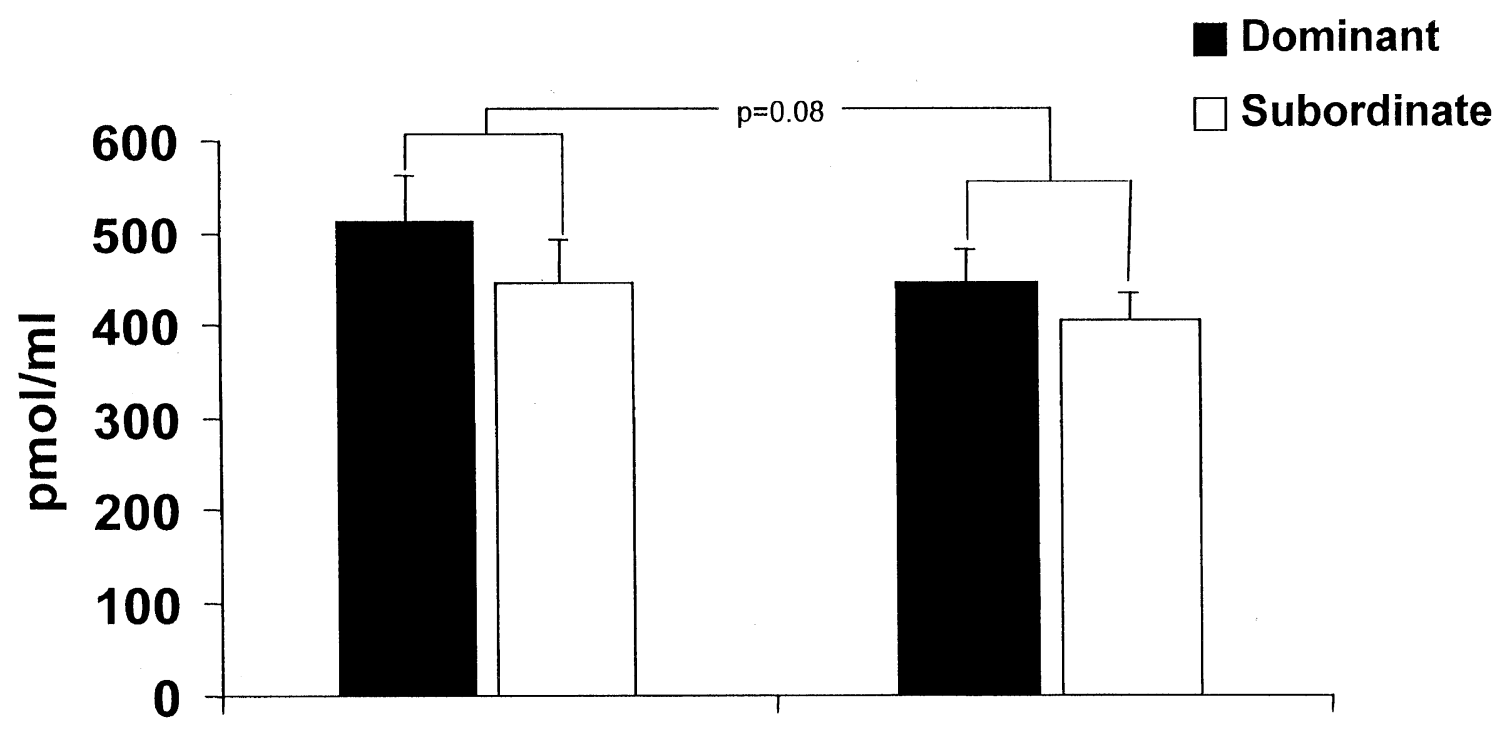

\section{Luteal}

Follicular

Figure 3. CSF 5-HIAA concentrations (mean + standard error) in the dominant $(\mathrm{n}=8)$ and subordinate $(\mathrm{n}=9)$ animals that exhibited ovulatory menstrual cycles as determined by plasma progesterone concentrations in the period during which CSF samples were collected. Statistical significance reflects the effect of menstrual cycle phase $\left(\mathrm{F}_{\text {PHASE }}\right)$. 
Table 3. Correlations for Females in Study $2, n=21^{\mathrm{a}}$

\begin{tabular}{|c|c|c|c|c|c|c|c|}
\hline & MHPG & HVA & HIAA & $\begin{array}{c}\text { Average }^{b} \\
\text { Weight }\end{array}$ & $\begin{array}{c}\text { Final b }^{\text {b }} \\
\text { Weight }\end{array}$ & Progesterone $^{c}$ & Rank \\
\hline MHPG & ---- & 0.36 & $0.73^{* *}$ & -0.04 & 0.08 & -0.19 & -0.20 \\
\hline HVA & & ---- & $0.67^{* *}$ & -0.12 & -0.22 & 0.09 & $0.57^{*}$ \\
\hline HIAA & & & ---- & -0.11 & 0.17 & 0.02 & 0.08 \\
\hline Average Weight & & & & ---- & $0.95^{* *}$ & 0.38 & 0.43 \\
\hline Final Weight & & & & & ---- & 0.37 & 0.24 \\
\hline Progesterone & & & & & & ---- & $0.53^{*}$ \\
\hline
\end{tabular}

disorder and reduced serotonergic activity (FitzGerald et al. 1997). The monkey data suggest there may be a typical luteal phase increase in serotonin neurotransmission, perhaps induced by the rise in periovulatory estrogen characteristic of Old World monkeys and apes. If the luteal phase increase in serotonergic activity were blunted (e.g., by estrogen deficiency), an increased vulnerability to premenstrual dysphoric disorder could result. Unlike 5-HIAA, CSF concentrations of HVA and MHPG did not vary significantly across the menstrual cycle. Finally, there were no significant associations among body weights, dominance, and CSF monoamine metabolite concentrations; such associations were possibly obscured by the relative uniformity of age and size within each study and the fact that all animals were abundantly fed with similar atherogenic diets. Dietary fat and cholesterol may increase serotonergic activity (Kaplan et al. 1996). It is therefore possible that the feeding of an atherogenic diet in both studies could have reduced the number of animals with low concentrations of CSF 5-HIAA, potentially obscuring an association with dominance. On the other hand, these experimental diets are modeled on those typically consumed by people in industrialized societies. Furthermore, changes in dietary composition in our studies are not associated with alterations in dominance status.

Notably, social dominance was stable over time under the conditions of housing obtaining in these studies. That is, high and low ranking monkeys generally retained their relative positions in the group hierarchies, a finding observed previously even in studies that involved repeated reorganization of group memberships (Kaplan and Manuck 1989; Shively and Kaplan 1991). Moreover, behavioral data in the males confirmed that animals that were judged dominant and subordinate on the basis of fight outcomes also differed significantly in their display of facial expressions and postures, their total rates of fight wins and losses, and in at least one af- filiative behavior (the percentage of time being groomed). These data suggest that the behavioral expression of dominance in the current studies did not differ in its essentials from that reported in other macaque populations, both captive and free-living (e.g., Sade 1967, 1973; Bernstein 1976; Bernstein and Cooper 1999).

The increased CSF HVA is consistent with results of a study in cynomolgus females that demonstrated that prolactin responses to D2 receptor blockade by haloperidol challenge were higher in dominants than among subordinate animals, indicating greater tonic D2 receptor mediated inhibition of prolactin release (Shively 1998). It is difficult to reconcile these two observations suggesting greater functional dopaminergic activity in dominants with a report of elevated D2 receptor binding among dominants of the same species (Grant et al. 1998) . In this latter study, greater striatal D2 receptor binding in dominant females as compared with subordinates was assessed by positron emission tomography (PET) and using the radioligand $\left[{ }^{18} \mathrm{~F}\right] 4$-fluoroclebopride $\left(\left[{ }^{18} \mathrm{~F}\right] \mathrm{FCP}\right)$. Perhaps the failure to distinguish between ventral striatum, which is part of the limbic system, and dorsal striatum, which is part of the motor system, may explain the discrepant receptor binding results. It has been shown that ventral striatal activity can differ from the dorsal striatum, reflecting different regulatory effects (Drevets et al. 1999).

The positive association of HVA concentrations with social dominance is consistent with at least two interpretations: (1) that changes in dopamine function follow acquisition of social rank; or (2) that variation in dopamine function precedes (and may facilitate) rank differentiation. The former seems less likely because stress alone increases dopaminergic activity and subordinate animals are typically thought to experience more stress. For example, acute exposure to stress can increase dopamine metabolism and release in terminal ar- 
eas of the mesocorticolimbic dopamine system in rodents (e.g., Ortiz et al. 1996). Stress may also alter dopaminergic activity in human subjects, as indicated by changes in plasma and urine HVA concentrations in response to a variety of psychosocial challenges (e.g., Gruen and Baron 1984; Breier 1989; Sumiyoshi et al. 1998; Posener et al. 1999). Furthermore, in human subjects the stress induced by acute glucose deprivation causes a reversible decrease in striatal binding to the D2/D3 receptor ligand $\left[{ }^{11} \mathrm{C}\right]$ raclopride, an effect similar to the lower D2 binding to $\left[{ }^{18} \mathrm{~F}\right] \mathrm{FCP}$ observed in subordinate, as compared with dominant, female cynomolgus monkeys (Grant et al. 1998; Adler et al. 2000). Finally, previous reports from our laboratory indicate that subordinate monkeys have enlarged adrenal glands and display an exaggerated cortisol response to ACTH stimulation, both signs of stress (Shively and Kaplan 1984; Kaplan et al. 1986). Overall, the higher HVA concentrations in dominant monkeys indicate an effect that exceeds any increase in dopamine function in response to the increased stress of subordinate status.

Conversely, stable individual differences in monoaminergic activity which have been noted by previous investigators (Higley et al. 1996a; Raleigh et al. 1992) may predispose animals to attain dominant or subordinate status, at least under some conditions. In natural groupings of macaques and some baboons (Papio hamadryas), the determination of dominance is often related to mother's rank, the age and sex of siblings, and direct support provided by both kin and life-long peers (e.g., Sade 1967; Hausfater 1975). Similar patterns are observed in captivity in the presence of an appropriate demographic structure (Bernstein 1981). In the unisexual groups studied here, however, kin and life-long peers were absent, and all monkeys were fully mature adults. Under such environmental and demographic constraints, an animal's likelihood of achieving and sustaining high or low rank may reflect underlying dimensions of temperament, which in turn, may covary with interindividual variability in neurobiological systems. For example, numerous investigations in both people and animals link dopaminergic function positively to exploratory behavior, assertiveness, aggressiveness, reward seeking, and positive emotionality-all characteristics related conceptually to social dominance (Gray 1987; Cloninger 1988; Depue and Iacono 1989; Zuckerman 1991; Depue et al. 1994; Depue 1995; Zuckerman 1995). Hence, one interpretation of the HVA findings is that the relatively higher metabolite concentrations of dominant animals represent dopaminergic potentiation of the expression of certain behaviors that lead animals to become dominant in small, unisexual groups initially composed of social strangers.

Serotonergic function may also represent an antecedent or consequence of relative social status, as we observed an inverse association between rank and 5-HIAA concentrations in males (when this relation was adjusted for concomitant variability in HVA). In this regard, the high positive correlation of HVA and 5-HIAA concentrations-possibly reflecting commonalties in their metabolism, but probably not in the regulation of their transport (e.g., Jibson et al. 1990) — may have obscured the underlying, inverse association otherwise existing between dominance and 5-HIAA. If, as suggested above, dominance is viewed as having a trait component, one interpretation of this result is that serotonergic and dopaminergic activity independently influence dominance outcomes by facilitating different classes of behavior. Hence, dopaminergic potentiation of reward seeking may provide one path to dominant status, whereas heightened impulsivity, aggressiveness, or risk taking (often associated with low-serotonergic activity) may lead to the same outcome in contests among animals. The low 5-HIAA of dominant males is consistent with the lower prolactin responses to fenfluramine (an indirect index of central serotonergic activity) reported in dominant as compared with subordinate female cynomolgus monkeys (Shively et al. 1995), and with lower CSF 5-HIAA concentrations in dominant than subordinate talapoin monkeys (Yodyingyuad et al. 1985). Furthermore, the presence of a correlation between dominance and low CSF 5-HIAA in males, but not females, is reminiscent of a similar sex difference in humans relating low serotonergic activity to aggression-associated traits (e.g. Manuck et al. 1998). Hence, females may exhibit a different relationship between dominance or aggression and serotonergic function compared with males. In that regard it is noteworthy that one group reported higher CSF 5-HIAA concentrations in dominant female rhesus monkeys, in comparison to their low ranking counterparts (Higley et al. 1996a), while another reported facilitation of high rank in vervet males following administration of a serotonergic agonist (Raleigh et al. 1991).

Differences in species and environmental conditions may help reconcile our findings with these latter two studies, which were conducted in relatively large heterosexual groupings maintained in outdoor enclosures. Regarding species, a number of studies suggest that cynomolgus macaques are higher in autonomic and hypopthalamic-pituitary-adrenocortical responsivity than other macaques, and may thus be categorized as "hyper reactive" (Clarke et al. 1988; Clarke and Boinski 1995). Hence, variation in central nervous system characteristics could contribute to the differences observed among macaque species. Regarding environment, the tightly constrained social and physical conditions characterizing the present studies allowed neither for escape nor exploitation of social resources-genealogical affiliations and long-term peer associations-typically used by monkeys to mediate dominance outcomes. Animals achieving dominant status under such circumstances 
may differ temperamentally, and hence in their associated monoamine correlates, from monkeys categorized as dominant in a single, larger heterosexual grouping with a longer and more complex social history. In turn, such speculation regarding environmental context is consistent with the view that dominance status represents an outcome specific to a particular social setting, rather than an inherent trait of individuals. As a result, it is perhaps not surprising that dominants in one social context are often subordinate in another (Bernstein 1981). Nonetheless, recent studies in captive rhesus monkeys indicate trait-like stability in the characteristic of "confidence", which combines assertiveness and aggressiveness and may thus contribute to the outcome of dominance interactions (Capitanio 1999).

Conclusions regarding the current data are necessarily constrained by a number of factors. Among these is the reliance on CSF metabolite concentrations as the sole index of central monoaminergic activity. The metabolites reflect general neuronal activity because a small proportion of released neurotransmitter is metabolized by monoamine oxidase after release and reuptake at the nerve terminal and before vesicular uptake. However, these metabolites are also affected by factors that alter catabolic rates independently of neuronal firing, and thus can only be considered indirect indices of neuronal activity (see review in Commissiong 1985). Moreover, it is not clear which brain regions are contributing to the observed differences in HVA. Another limitation is the reliance on a single CSF sample in our study of males. Furthermore, the relatively small numbers of animals provided limited power to detect significant associations. It is noteworthy that (cf., first paragraph of Monoamine Metabolites and Dominance Status) the same CSF HVA differentiation of dominants and subordinates was observed in the larger sample of 75 males $-2 / 3$ of which were housed in groups that were repeatedly reorganizedfrom which the current study animals were drawn (dominants: 1388 (72 S.E.M.) pmol/ml, subordinates: 1181 (33 S.E.M.) pmol $/ \mathrm{ml}, t_{65}=2.76, p<.01$ ). Finally, although the data revealed a consistent association across males and females between elevated CSF HVA concentrations and dominant social status, it remains unclear whether this HVA variation preceded or followed social rank acquisition. Prospective investigations evaluating the effects of dopaminergic agonists and antagonists on the acquisition and stability of dominance rank in groups of unrelated monkeys could help resolve this question.

\section{ACKNOWLEDGMENTS}

Research was supported by the following grants: $\mathrm{MH} 46745$ (JJM), HL 40962 (SBM), HL 45666 (JRK).
Elizabeth Nicks, Dewayne Cairnes, and Melissa Ayers aided in the collection of cerebrospinal fluid. Yung-yu Huang measured the metabolite concentrations in cerebrospinal fluid.

\section{REFERENCES}

Adams MR, Kaplan JR, Koritnik DR (1985): Psychosocial influences on ovarian endocrine and ovulatory function in Macaca fascicularis. Physiol Behav 35:935-940

Adler CM, Elman I, Weisenfeld N, Kestler L, Pickar D, Breier A (2000): Effects of acute metabolic stress on striatal dopamine release in healthy volunteers. Neuropsychopharmacology 22:545-550

Altmann J (1974): Observational study of behavior: sampling methods. Behaviour 49:337-367

Bernstein IS (1976): Dominance, aggression and reproduction in primate societies. J Theor Biol 60:459-472

Bernstein IS (1981): Dominance: the baby and the bathwater. The Behavioral and Brain Sciences 4:419-457

Bernstein IS, Cooper MA (1999): Dominance in assamese macaques (Macaca assamensis). Am J Primatol 48:283-289

Breier A (1989): Experimental approaches to human stress research: Assessment of neurobiological mechanisms of stress in volunteers and psychiatric patients. Biol Psychiatry 26:438-462

Butovskaya M, Kozintsev A, Welker C (1995): Grooming and social rank by birth: the case of Macaca fascicularis. Folia Primatol 65:30-33

Capitanio JP (1999): Personality dimensions in adult male rhesus macaques: prediction of behaviors across time and situation. Am J Primatol 47:299-320

Clarke AS, Boinski S (1995): Temperament in nonhuman primates. Am J Primatol 37:103-126

Clarke AS, Mason WA, Moberg GP (1988): Interspecific contrasts in responses of macaques to transport cage training. Lab Anim Sci 38:305-309

Cloninger CR (1988): A unified biosocial theory of personality and its role in the development of anxiety states: a replay to commentaries. Psychiatr Dev 6:83-120

Cohen S, Line S, Manuck SB, Rabin BS, Heise ER, Kaplan JR (1997): Chronic social stress, social status, and susceptibility to upper respiratory infections in nonhuman primates. Psychosom Med 59:213-221

Commissiong JW (1985): Monoamine metabolites: their relationship and lack of relationship to monoaminergic neuronal activity. Biochem Pharmacol 34:1127-1131

Depue RA (1995): Neurobiological factors in personality and depression. European Journal of Personality 9:413-439

Depue RA, Iacono WG (1989): Neurobehavioral aspects of affective disorders. Annu Rev Psychol 40:457-492

Depue RA, Luciana M, Arbisi P, Collins P, Leon A (1994): Dopamine and the structure of personality: relation of agonist-induced dopamine activity to positive emotionality. J Pers Soc Psychol 67:485-498

Drevets WC, Price JC, Kupfer DJ, Kinahan PE, Lopresti B, Holt D, Mathis C (1999): PET measures of amphetamine-induced dopamine release in ventral versus dorsal striatum. Neuropsychopharmacology 21:694-709 
Eriksson E, Alling C, Andersch B, Andersson K, Berggren U (1994): Cerebrospinal fluid levels of monoamine metabolites. A preliminary study of their relation to menstrual cycle phase, sex steroids, and pituitary hormones in healthy women and in women with premenstrual syndrome. Neuropsychopharmacology 11:201-213

FitzGerald M, Malone KM, Li S, Harrison WM, McBride PA, Endicott J, Cooper T, Mann JJ (1997): Blunted serotonin response to fenfluramine challenge in premenstrual dysphoric disorder. Am J Psychiatry 154:556-558

Grant KA, Shively CA, Nader MA, Ehrenkaufer RL, Line SW, Morton TE, Gage HD, Mach RH (1998): Effect of social status on striatal dopamine $\mathrm{D}_{2}$ receptor binding characteristics in cynomolgus monkeys assessed with positron emission tomography. Synapse 29:80-83

Gray JA (1987): The neuropsychology of emotion and personality. In Stahl SM, Iverson SD, Goodman EC, (eds), Cognitive Neurochemistry. Oxford, UK, Oxford University Press, pp 171-190

Gruen R, Baron M (1984): Stressful life events and schizophrenia: Relation to illness onset and family history. Neuropsychobiology 12:206-208

Hausfater G (1975): Dominance and reproduction in baboons (Papio cynocephalus). Contrib Primatol 7:1-150

Higley JD, Suomi SJ, Linnoila M (1991): CSF monoamine metabolite concentrations vary according to age, rearing, sex, and are influenced by the stressor of social separation in rhesus monkeys. Psychopharmacology 103: $551-556$

Higley JD, King ST Jr, Hasert MF, Champoux M, Suomi SJ, Linnoila M (1996a): Stability of interindividual differences in serotonin function and its relationship to severe aggression and competent social behavior in rhesus macaque females. Neuropsychopharmacology 14:67-76

Higley JD, Mehlman PT, Poland RE, Taub DM, Vickers J, Suomi SJ, Linnoila M (1996b): CSF testosterone and 5-HIAA correlate with different types of aggressive behaviors. Biol Psychiatry 40:1067-1082

Jibson M, Faull KF, Csernansky JG (1990): Intercorrelations among monoamine metabolite concentrations in human lumbar CSF are not due to a shared acid transport system. Biol Psychiatry 28:595-602

Kaplan JR, Manuck SB (1989): The effect of propranolol on behavioral interactions among adult male cynomolgus monkeys (Macaca fascicularis) housed in disrupted social groupings. Psychosom Med 51:449-462

Kaplan JR, Manuck SB, Clarkson TB, Lusso FM, Taub DM (1982): Social status, environment, and atherosclerosis in cynomolgus monkeys. Arteriosclerosis 2:359-368

Kaplan JR, Adams MR, Koritnik DR, Rose JC, Manuck SB (1986): Adrenal responsiveness and social status in intact and ovariectomized Macaca fascicularis. Am J Primatol 11:181-193

Kaplan JR, Manuck SB, Gatsonis C (1990): Heart rate and social status among male cynomolgus monkeys (Macaca fascicularis) housed in disrupted social groupings. Am J Primatol 21:175-187

Kaplan JR, Shively CA, Fontenot MB, Morgan TM, Howell SM, Manuck SB, Muldoon MF, Mann JJ (1994): Demonstration of an association among dietary cholesterol, central serotonergic activity, and social behavior in monkeys. Psychosom Med 56:479-484

Kaplan JR, Adams MR, Anthony MS, Morgan TM, Manuck SB, Clarkson TB (1995): Dominant social status and contraceptive hormone treatment inhibit atherogenesis in premenopausal monkeys. Arterioscler Thromb Vasc Biol 15:2094-2100

Kaplan JR, Fontenot MB, Manuck SB, Muldoon MF (1996): The influence of dietary lipids on agonistic and affiliative behavior in Macaca fascicularis. Am J Primatol 38:333-347

Kaplan JR, Phillips-Conroy J, Fontenot MB, Jolly CJ, Fairbanks LA, Mann JJ (1999): Cerebrospinal fluid monoaminergic metabolites differ in wild anubis and hybrid (anubis-hamadryas) baboons: possible relationships to life history and behavior. Neuropsychopharmacology 20:517-524

Lewis MH, Gluck JP, Beauchamp AJ, Keresztury MF, Mailman RB (1990): Long-term effects of early social isolation in Macaca multatta: changes in dopamine receptor function following apomorphine challenge. Brain Res 513:67-73

Manuck SB, Flory JD, McCaffery JM, Matthews KA, Mann JJ, Muldoon MF (1998): Aggression, impulsivity, and central nervous system serotonergic responsivity in a nonpatient sample. Neuropsychopharmacology 19:287-299

Netter P, Rammsayer T (1991): Reactivity to dopaminergic drugs and aggression-related personality traits. Personality and Individual Differences 12:1009-1017

Ortiz J, Fitzgerald LW, Lane S, Terwilliger R, Nestler EJ (1996): Biochemical adaptations in the mesolimbic dopamine system in response to repeated stress. Neuropsychopharmacology 14:443-452

Posener JA, Schatzberg AF, Williams GH, Samson JA, McHale NL, Bessette MP, Schildkraut JJ (1999): Hypothalamic-pituitary-adrenal axis effects on plasma homovanillic acid in man. Biol Psychiatry 45:222-228

Raleigh MJ, Brammer GL, McGuire MT (1983): Male dominance, serotonergic systems, and the behavioral and physiological effects of drugs in vervet monkeys (Cercopithecus aethiops sabaeus). Prog Clin Biol Res 131:185-197

Raleigh MJ, McGuire MT, Brammer GL, Pollack DB, Yuwiler A (1991): Serotonergic mechanisms promote dominance acquistion in adult male vervet monkeys. Brain Res 559:181-190

Raleigh MJ, Brammer GL, McGuire MT, Pollack DB, Yuwiler A (1992): Individual differences in basal cisternal cerebrospinal fluid 5-HIAA and HVA in monkeys. The effects of gender, age, physical characteristics, and matrilineal influences. Neuropsychopharmacology 7:295-304

Sade D (1967): Determinants of dominance in a group of free-ranging rhesus monkeys. In Altmann S (ed), Social Communication among Primates. New York, Academic Press, pp 99-114

Sade DS (1973): An ethogram for Rhesus monkeys. I. Antithetical contrasts in posture and movement. Am J Phys Anthropol 38:537-542

Scheinin M, Chang WH, Kirk KL, Linnoila M (1983): Simultaneous determination of 3-methoxy-4-hydroxyphenylglycol, 5-hydroxyindoleacetic acid, and homovanillic 
acid in cerebrospinal fluid with high performance liquid chromatography using electrochemical detection. Anal Biochem 131:246-253

Shively CA (1998): Social subordination stress, behavior, and central monoaminergic function in female cynomolgus monkeys. Biol Psychiatry 44:882-891

Shively C, Kaplan J (1984): Effects of social factors on adrenal weight and related physiology of Macaca fascicularis. Physiol Behav 33:777-782

Shively CA, Kaplan JR (1991): Stability of social status rankings of female cynomolgus monkeys, of varying reproductive condition, in different social groups. Am J Primatol 23:239-245

Shively CA, Fontenot MB, Kaplan JR (1995): Social status, behavior and central serotonergic responsivity in female cynomolgus monkeys. Am J Primatol 37:333-339

Silk JB (1987): Social behavior in evolutionary perspective. In Smuts BB, Cheney DL, Seyfarth RM, Wrangham RW, Struhsaker TT (eds), Primate Societies. Chicago, The University of Chicago Press, pp 318-329

Sumiyoshi T, Yotsutsuji Y, Kurachi M, Itoh H, Kurokawa K, Saitoh O (1998): Effect of mental stress on plasma homovanillic acid in healthy human subjects. Neuropsychopharmacology 19:70-73
Walters JR, Seyfarth RM (1987): Conflict and cooperation. In Smuts BB, Cheney DL, Seyfarth RM, Wrangham RW, Struhsaker TT (eds), Primate Societies. Chicago, The University of Chicago Press, pp 306-317

Welker C, Luhrmann B, Meinel W (1979): Behavioral sequences and strategies of female crab-eating macaques, Macaca fascicularis Raffles, 1821, during group formation studies. Behavior 10:219-237

Wiggins JS, Pincus AL (1992): Personality: structure and assessment. Annu Rev Psychol 43:473-504

Wiggins JS, Trapnell PD (1996): A dyadic-interactional perspective on the five-factor model. In Wiggins JS (ed), The Five-Factor Model of Personality. New York, The Guilford Press, p 88

Yodyingyuad U, de la Riva C, Abbott DH, Herbert J, Keverne EB (1985): Relationship between dominance hierarchy, cerebrospinal fluid levels of amine transmitter metabolites (5-hydroxyindole acetic acid and homovanillic acid) and plasma cortisol in monkeys. Neurosci 16:851-858

Zuckerman M (1991): Psychobiology of Personality. Cambridge, UK, Cambridge University Press

Zuckerman M (1995): Good and bad humors: biochemical bases of personality and its disorders. Psychological Science 6:325-332 